\title{
A Survey on Facial Expression Recognition Technology and Its Use in Virtual Systems
}

\author{
Haleema Inam ${ }^{\text {a }}$, Asma Malik ${ }^{\text {a }}$, Marina Hayat ${ }^{\text {a }}$, Aliya Ashraf ${ }^{\text {a }}$ \\ ${ }^{a}$ Department of Software Engineering, Fatima Jinnah Women University, The Mall Rawalpindi 46000, \\ Pakistan
}

\begin{abstract}
Human Facial expressions are the most expressive way to display their non verbal emotions. Human can easily detect and interpret faces to understand the emotions of the person in front of them. An important aspect of facial expression recognition is its implementation in the virtual domain. Different apps for auto-face recognition can be an important factor for the growth of components of natural human-machine interfaces. Many attempts are made from few years for the development of automated systems for which will detect human face expressions and in turn their moods. This paper gives a survey over the expertise used for human moods detection and recognition of facial expression recently.
\end{abstract}

Index Terms: Emotion, Facial Expression recognition, Mood Tacking, Moodmap app, Sensor.

(C) 2015 Published by MECS Publisher. Selection and/or peer review under responsibility of the Research Association of Modern Education and Computer Science.

\section{Introduction}

In virtual meetings facial expression recognition is the most demanding technology and many scientists are working on this technology. The reason is that in virtual meetings a main problem is obviously the lack of face to face communication. This type of contact is referred as communication of gestures and moods including eye contact. Everything that you say depend upon one's mood that is in front of you and you also need a feedback expression while virtual meetings lack this factor. A survey is made on the work of different people. Their techniques and researches are analyzed which have their own cons and pros in the domain of virtual meetings. Virtual masking is one of the interesting app for face expression recognition in which people hide their faces by only showing the expressions through some technology used. Moods detection in diverse backgrounds helps to improve the interpersonal communication skills which are important especially in group job.

The practice of a mood identification app that is MoodMap app is considered a good way for tracking or recording the mood of your colleagues in a virtual meeting in order to infer the results about how they feel in

* Corresponding author. Tel.:

E-mail address: 
the meeting and how much they are satisfied from the ideas discussed in a particular meeting. There are many problems regarding the performance of this auto face expression detection technique which mainly includes detection of an image segment as a face, categorization of various face curves and lines in different emotion categories and extraction of information from a facial appearance. This paper provides an overview of the parameter analysis required for development of an automated expression recognition system

\section{Literature Review}

An exploration was led in inclination acknowledgment errand in which thirty three target clients were arranged in dismal and cheerful temperaments to peruse their feelings and at that point where they were requested to perform some feeling acknowledgment undertaking in which their eye developments were record and hence an essential strategy used to peruse their feelings were eye development thought. The outcomes demonstrated that diverse conditions of inclinations sexual orientations and data frameworks like interface outline or the application environment put an immediate influence on the feeling acknowledgment exactness.

The utilization of a state of mind acknowledgment application that was Mood Map application and that was examined where this application was used to research the own inclination and colleagues states of mind over distinctive times to judge about their encounters and make strong conclusions in which the greater part of the individuals were intrigued. Besides this application was utilized for the investigation of disposition following. The temperament discovery was talked about by utilizing some music mental speculations. Diverse music clasps were perused from music information to characterize different qualities of sound like timbre, pitch and power. A fitting system was introduced and test work was likewise done in this an appreciation where a calculation was exhibited to which a demonstrated accommodating in discovery of state of mind from a music clasp. Highlight extraction was additionally talked about in segment 2 which incorporate a timbre, a beat and the force extraction.

It was thought that by examining the correspondence history and application use models which can factually surmises the client's every day state of mind normal with an introductory exactness of the $66 \%$ of which the continuously enhances, to the precision of $93 \%$ after a two-month customized preparing period. So after that study the term Mood Scope was utilized, in which it construes the temperament of its client in view of how the cell phone is utilized, MoodScope is a 'sensor' which approaches a mental condition of the client and gives disposition as an imperative data to connection mindful figuring.

The examination was done to create humanoid exhibition hall visit guide robot that performs natural multimodal communication with different individuals, the robots use a discourse and an outward appearance and eye look to communicate with the individuals. While speaking with the individuals the robot uses varying media data and utilization human like arm motions amid a communication. While existing graphical arrangements were suitable for virtual operators and explaining an arm directions of the physically epitomized robots obliges that we consider the difficulties of robot progress inside a continuous signal system.

In it the client influence acknowledgment from feature was often tuned to distinguish quickly the enthusiastic conditions of instead of longer term and of the more steady full of feeling states, for example, state of mind. In this they propose a non-straight computational model for overcoming any and all hardships between the perceived feelings of an individual caught by a feature and the general state of mind of individual, for a trial acceptance, the feelings and the disposition were human a documentations on a full of feeling visual database that were made deliberately. Taking into account highlights portraying idiosyncrasies and changes in the client's enthusiastic state and own framework had the capacity foresee the comparing temperament well above chance and more precisely than existing models. Frameworks and techniques were accommodated performing center recognition, referential vagueness determination and temperament characterization as per multi-modular data information, in differing working situation and by keeping in mind the end goal to give a compelling conversational processing environment for one or more clients.

Biometric validation depends on an individual's internal attributes and characteristics where they proposes the dynamic confirmation of the framework on a cell phone that depends on two biometric modalities: 3D 
motions and face acknowledgment and their methodology was to consolidate 3D signal and face acknowledgment in a nonintrusive and unconstrained environment. They display the outline, usage and assessment of a hearty, ongoing face elucidation motor for cell phones, called Visage that empowers another class of face-mindful applications for cell phones. Results show that Visage was elective in different certifiable situations. Moreover they added to two unmistakable verification of-idea applications, Streetview+ and Mood Profiler driven by Visage.

Six perpetual Facial highlights like eyebrows, eye, mouth and nose were removed by utilizing facial geometry, edge projection investigation and separation measure and highlight vector was shaped by considering tallness and width of left eye and an eyebrow; stature and the width of the right eyebrow; the tallness and the width of nose and so forth, the acknowledgment of the order of a human outwards appearance by PC was an imperative issue to create programmed outward appearance acknowledgment framework in vision group. In it the Neural Network model was built for JAFEE Face Database for frontal perspective facial pictures. For right eye and eyebrow additionally particular edge worth was picked for killing the external portions. Segment was the lower bit, on a off chance that its esteem was more prominent than centx and centy where centx and centy were $\mathrm{x}$ - and $\mathrm{y}$ directions of middle of a picture.

The acknowledgment of human feeling was characterize by the 2D passionate model and by the utilization of highlight based outward appearance acknowledgment while utilizing machine gaining instrument. . The proposed framework comprises of human feeling demonstrating, outward appearance based feeling acknowledgment and feeling emotional picture exchanged even sincerely exchanged picture substance, they changed over the sharing of data picture to feeling emotional picture utilizing passionate shading wheel. In most the cutting edge innovations on feeling acknowledgment, highlights were separate from a picture, discourse and bio-signs and were all characterized into particular enthusiastic classifications in view of pertained acknowledgment models. Feeling emotional shading picture could be delivered by mapping the shading palette of data picture to the enthusiastic shading palette. The highlights of good facial acknowledgment were examined. In it the outflow acknowledgment's highlights were talked about in a manner that it must be of completely programmed that must have an ability to work with the feature nourishes and pictures, must work continuously and must have the capacity to perceive unconstrained declarations. Alongside the prototypic declarations, it must have the capacity to perceive an entire scope of various outflows as well that must be powerful against diverse lighting conditions has the capacity of working tolerably well even in the vicinity of impediments and must be inconspicuous. The pictures and feature encourages don't need to be preprocess. That should be individual autonomous and must deal with individuals from diverse societies and distinctive skin hues.

\section{Analysis}


Table 1. Quality Parameters, Their Meaning and Possible Values

\begin{tabular}{|c|c|c|c|}
\hline Serial \# & Parameters & Meanings & Possible Values \\
\hline 1 & Extendibility & $\begin{array}{l}\text { New features can be easily adapted by a } \\
\text { system or techniques }\end{array}$ & Yes, No, and not defined \\
\hline 2 & Performance & Process of performing task or functions & Yes, No, and not defined \\
\hline 3 & Integrity & $\begin{array}{l}\text { Protection against unauthorized access } \\
\text { protecting programs and software }\end{array}$ & Yes, No, and not defined \\
\hline 4 & Reusability & $\begin{array}{l}\text { How well the modules can be reused in } \\
\text { another framework }\end{array}$ & Yes, No, and not defined \\
\hline 5 & Robustness & $\begin{array}{l}\text { Proper execution of a system under cases } \\
\text { not secured by the prerequisite. This is } \\
\text { reciprocal to accuracy. }\end{array}$ & Yes, No, and not defined \\
\hline 6 & Efficiency & $\begin{array}{l}\text { While using minimum resources to produces } \\
\text { high throughput }\end{array}$ & Yes, No, and not defined \\
\hline 7 & Complexity & To what extent modules are inter-related & Yes, No, and not defined \\
\hline 8 & Security & $\begin{array}{l}\text { nobody can get to the individual data of a } \\
\text { particular individual }\end{array}$ & Yes, No, and not defined \\
\hline 9 & Cost effective & Relation of cost to the productive process & Yes, No, and not defined \\
\hline 10 & Reliability & $\begin{array}{l}\text { To perform functions without experiencing } \\
\text { failure. }\end{array}$ & Yes, No, and not defined \\
\hline 11 & Case study & Example in real time & Yes, No, and not defined \\
\hline 12 & Effortless & $\begin{array}{l}\text { The nature of a framework that makes the } \\
\text { client to utilize it effectively }\end{array}$ & Yes, No, and not defined \\
\hline 13 & Compatibility & $\begin{array}{l}\text { Programming that is made out of } \\
\text { components that can undoubtedly }\end{array}$ & Yes, No, and not defined \\
\hline 14 & Maintainability & $\begin{array}{l}\text { The simplicity of changing the programming } \\
\text { to redress deformities or meet new } \\
\text { necessities }\end{array}$ & Yes, No, and not defined \\
\hline 15 & Virtualization & $\begin{array}{l}\text { To how much surviving the paper work is } \\
\text { digitalized }\end{array}$ & Yes, No, and not defined \\
\hline 16 & Ease of use & Easy to use for everyone & Yes, No, and not defined \\
\hline 17 & Portability & Move from system to system easily & Yes, No, and not defined \\
\hline 18 & Diversity & $\begin{array}{l}\text { The amount of a framework can perform in } \\
\text { the alterable environment }\end{array}$ & Yes, No, and not defined \\
\hline 19 & Scalability & $\begin{array}{l}\text { Capacity to adapt up and Perform under an } \\
\text { expanded or growing workload. }\end{array}$ & Yes, No, and not defined \\
\hline 20 & Availability & Available all the time & Yes, No, and not defined \\
\hline
\end{tabular}




\section{Quality Parameters Analysis}

\subsection{Extensibility}

The system designed should be easy to adapt to new specification. This field is all about the extending new things in face recognition technologies. Alejandro Jaims, NicuSebe, MarenBennewitz, Dominik Joho, Filex Faber, Judith A.Redi and David F.Dinges discusses the extensibility feature in system used.

\subsection{Performance}

Performance of a system is defined by backtracking and cost of time taken for the completion of a job. Alejandro Jaims, NicuSebe, Dominik Joho, Filex Faber, Judith A.Redi David F.Dinges and MarenBennewitz. ensure performance criteria to be fulfilled for the applications used.

\subsection{Integrity}

Protection of any system used against illegal users. Face recognition automatic systems should be well defined to integrity. MarenBennewitz, Dominik Joho, Filex Faber, Judith A.Redi and David F.Dinges considered that face expression recognition can be modified for integrity meeting

\subsection{Reusability}

Existing techniques can be reused to develop other systems. Modularization is the technique for achieving reusability in application of mood tracking.

\subsection{Robustness}

Healthy to cope with specific errors during execution., Dominik Joho, Filex Faber, Judith A.Redi and David F.Dinges and Aljendro Jaims ensured the importance of this feature.

\subsection{Efficiency}

More work in low utilization of resources. This is not much considered in paper.

\subsection{Complexity}

Application which is too large and complicated is not adapted by most of the people.

\subsection{Security}

Ability of a system to prevent unwanted access.

\subsection{Case Study}

No case study is used in the paper.

\subsection{Virtualization}


Creation of virtual version of something defines virtualization. This parameter is used in virtual meetings and apps. Angela Fecl and Ver-onica discuss to create virtual application for face expression recognition.

Table 2. Analysis Table of Parameters against Authors

\begin{tabular}{|c|c|c|c|c|c|c|c|c|c|c|c|}
\hline $\begin{array}{l}\text { Ser } \\
\text { ial } \\
\#\end{array}$ & Authors & $\begin{array}{l}\text { Exte } \\
\text { ndibi } \\
\text { lity }\end{array}$ & $\begin{array}{l}\text { Perfor } \\
\text { mance }\end{array}$ & $\begin{array}{l}\text { Inte } \\
\text { grit } \\
y\end{array}$ & $\begin{array}{l}\text { Reusa } \\
\text { bility }\end{array}$ & $\begin{array}{l}\text { Robus } \\
\text { tness }\end{array}$ & $\begin{array}{l}\text { Effic } \\
\text { iency }\end{array}$ & $\begin{array}{l}\text { Compl } \\
\text { exity }\end{array}$ & $\begin{array}{l}\text { Reliab } \\
\text { ility }\end{array}$ & $\begin{array}{l}\text { Case } \\
\text { Stud } \\
y\end{array}$ & $\begin{array}{l}\text { Virtua } \\
\text { lizatio } \\
n\end{array}$ \\
\hline 1 & $\begin{array}{l}\text { Petra C. Schmid et } \\
\text { al, } 2011\end{array}$ & $\mathrm{Y}$ & $\mathrm{Y}$ & $Y$ & $N$ & $Y$ & $Y$ & $Y$ & $\mathrm{Y}$ & $\mathrm{Y}$ & $\mathrm{Y}$ \\
\hline 2 & $\begin{array}{l}\text { Angela Fessl et al, } \\
2012\end{array}$ & $\mathrm{Y}$ & $\mathrm{Y}$ & $N$ & $N$ & $Y$ & $Y$ & $Y$ & $\mathrm{Y}$ & $\mathrm{Y}$ & $\mathrm{Y}$ \\
\hline 3 & Dan Liu et al, 2013 & $\mathrm{Y}$ & $\mathrm{Y}$ & $Y$ & $N$ & $Y$ & $Y$ & $N$ & $\mathrm{Y}$ & $\mathrm{Y}$ & $\mathrm{Y}$ \\
\hline 4 & $\begin{array}{l}\text { Tsen-Yao Chang, } \\
2005\end{array}$ & $\mathrm{Y}$ & $\mathrm{Y}$ & $Y$ & $Y$ & $Y$ & $N$ & $N$ & $\mathrm{Y}$ & $\mathrm{Y}$ & $\mathrm{Y}$ \\
\hline 5 & $\begin{array}{l}\text { Robert LiKamWa, et } \\
\text { al, 2013. }\end{array}$ & $\mathrm{Y}$ & $\mathrm{Y}$ & $N$ & $Y$ & $N D$ & $N$ & $Y$ & $\bar{Y}$ & $\bar{Y}$ & $\mathrm{Y}$ \\
\hline 6 & $\begin{array}{l}\text { Alejandro Jaimes et } \\
\text { al, } 2007\end{array}$ & $\mathrm{Y}$ & $\mathrm{Y}$ & $N$ & $Y$ & $Y$ & $Y$ & $N$ & $\mathrm{Y}$ & $\mathrm{Y}$ & $\mathrm{Y}$ \\
\hline 7 & $\begin{array}{l}\text { MarenBennewitz, et } \\
\text { al, } 2007\end{array}$ & $\mathrm{Y}$ & $\mathrm{Y}$ & $N D$ & $Y$ & $N$ & $Y$ & $N$ & $\mathrm{Y}$ & $\mathrm{Y}$ & $\mathrm{Y}$ \\
\hline 8 & $\begin{array}{l}\text { Christina } \\
\text { Katsimerou et al, } \\
2014\end{array}$ & $\mathrm{Y}$ & $\mathrm{Y}$ & $Y$ & $Y$ & $N D$ & $Y$ & $N$ & $\mathrm{Y}$ & $\mathrm{Y}$ & $\mathrm{Y}$ \\
\hline 9 & $\begin{array}{l}\text { David F. Dinges et } \\
\text { al, } 2005\end{array}$ & $\mathrm{Y}$ & $\mathrm{Y}$ & $Y$ & $Y$ & $N D$ & $Y$ & $Y$ & $\mathrm{Y}$ & $\mathrm{Y}$ & $\mathrm{Y}$ \\
\hline 10 & $\begin{array}{l}\text { Xiaochao Yang, et } \\
\text { al, } 2013\end{array}$ & $\mathrm{Y}$ & $\mathrm{Y}$ & $Y$ & $N$ & $Y$ & $Y$ & $N$ & $\mathrm{Y}$ & $\mathrm{Y}$ & $\mathrm{Y}$ \\
\hline 11 & $\begin{array}{l}\text { SeungTaek Ryoo, } \\
2013\end{array}$ & $\mathrm{Y}$ & $\mathrm{Y}$ & $N D$ & $Y$ & $N$ & $N D$ & $Y$ & $\mathrm{Y}$ & $\mathrm{Y}$ & $\mathrm{Y}$ \\
\hline 12 & $\begin{array}{l}\text { SeungTaek Ryoo et } \\
\text { al, } 2014\end{array}$ & $N D$ & $Y$ & $\mathrm{Y}$ & $\mathrm{Y}$ & $\mathrm{Y}$ & $\mathrm{Y}$ & $\mathrm{N}$ & $N D$ & $N$ & $Y$ \\
\hline 13 & $\begin{array}{l}\text { Vinay Bettadapura, } \\
2012\end{array}$ & $\mathrm{Y}$ & $\mathrm{Y}$ & $\mathrm{N}$ & $\mathrm{Y}$ & $\mathrm{Y}$ & $\mathrm{Y}$ & $\mathrm{N}$ & $\mathrm{Y}$ & $\mathrm{Y}$ & $\mathrm{Y}$ \\
\hline 14 & $\begin{array}{l}\text { S.P.Khandait et al, } \\
2012\end{array}$ & $\mathrm{Y}$ & $\mathrm{Y}$ & $N D$ & $\mathrm{Y}$ & $N D$ & $Y$ & $\mathrm{Y}$ & $\mathrm{Y}$ & $N$ & $Y$ \\
\hline 15 & $\begin{array}{l}\text { Bram van de Laar, } \\
2006\end{array}$ & $\mathrm{Y}$ & $N D$ & $\mathrm{~N}$ & $Y$ & $\mathrm{Y}$ & $\mathrm{Y}$ & $\mathrm{N}$ & $\mathrm{Y}$ & $\mathrm{Y}$ & $\mathrm{Y}$ \\
\hline
\end{tabular}

\section{Conclusion}

In this artifact a new methodology for difference image based facial expression recognition by making use of properties of eigenvector rottenness is anticipated. The anticipated policy abolishes the constraint of neutral image of the issue by synthesizing a virtual neutral image. Hence, it organizes for a way for expression recognition from a given expression encompassing test image based on difference image impression. The 
alteration image thus attained is designated as expression component image which imprisonments the information consistent to the expression of the test image. The legitimacy and adeptness of article trajectory was tested using several classifiers (FLDA, MLP and SVM) and possessions achieved validate the germaneness of expression component image as feature vector. A relative analysis relating to cataloging aptitude of several classifiers has also been accompanied and it has been originate that multiclass SVM outpace both MLP and FLDA. The paramount Recognition accuracy of approx. 92.4\% has been recounted using SVM classifier which is equivalent to the state-of-art methods.

The impartial of this survey was to give an ephemeral primer to researches towards automatic facial expression recognition systems. As I have discussed, the research interplanetary is really immense and had been going on for a long time towards this bearing. In order to study facial expression detection, I have divided the problem into three modules and defined them in order and then designated two systems which are using facial expression recognition. After going over the unabridged procedure, I can incline some possessions that a virtuous facial expression recognition system should have - Should be spontaneous and should run without human involvement or super- vision. Should be incapable to implement even if there is change in lighting condition, back-ground or other environmental changes. Should be able to distinguish expression from different camera viewing angles. Should be competent recognize expression from people of different age, color, sex, ethnicity, hairstyle, facial hair etc. Should be able to recognize expression even if the subject is wearing makeup, glasses, ornaments, tattoos, piercing etc. Should be able to recognize spontaneous expression as well as directed expressions. Should be able to perform sufficiently in presence of some degree of occlusion. Should be competent to exertion with images or video feeds.

\section{Future Work}

The future of facial expression recognition systems aspects really optimistic as researchers is trying to reject the time to converse with the machine. For example, we started with punch cards and had to acquiesce our jobs to a system to be capable to get results the next day, then we had our own pc where we started using mouse and keyboard to interrelate with the machine, now we have impressive touch screens where 'pinch to zoom' structures expressions like a no-brainer. I can emphatically see the impending where may be oblique your eyes would interpret into a machine instruction and you would not need peripheral input devices to intermingle with the machine. As we are facing voice assistant 'Siri' can listen to your audible instructions and future facial expression recognition associate would be able to carry out your expression based commands.

In the future we are planning to abstract the expression module by making procedure of patch-wise estimate on impartial subspace. Application of Artificial Wavelet Networks would also be interesting remaining to their local estimate abilities.

\section{References}

[1] Alejandro Jaimes and NicuSebe, "Multimodal Human Computer Interaction: A Survey", FXPAL, Japan, Fuji Xerox Co.,Ltd. alex.jaimes@fujixerox.co.jp, University of Amsterdam, The Netherlands, nicu@science.uva.nl, Publishing 2007.

[2] MarenBennewitz, Felix Faber, Dominik Joho and Sven Behnke, "Intuitive Multimodal Interaction with Communication Robot Fritz", University of Freiburg, Computer Science Institute, Germany, Publishing2007.

[3] Christina Katsimerou, Judith A. Redi, "Neural prediction of the user's mood from visual input", Multimedia Computing Group, Delft University of Technology, The Netherlands \{C.Katsimerou, J.A.Redi\}@tudelft.nl, Publishing 2014.

[4] David F. Dinges, Robert L. Rider, Jillian Dorrian, Eleanor L. McGlinchey, Naomi L. Rogers, 
ZigaCizman, Siome K. Goldenstein, Christian Vogler, SundaraVenkataraman, and Dimitris N. Metaxas "Optical Computer Recognition of Facial Expressions Associated with Stress Induced by Performance Demands", Aviation, Space, and Environmental Medicine • Vol. 76, No. 6, Section II • June 2005.

[5] Xiaochao Yang, Chuang-Wen You, Hong Lu, Mu Lin, Nicholas D. Lane, and Andrew T. Campbell, "Visage: A Face Interpretation Engine for Smartphone Applications", Dartmouth College, 6211 Sudiko Lab, Intel Lab, 2200 Mission College Blvd, Santa Clara, CA 95054, USA, Microsoft Research Asia, Publishing 2013.

[6] Petra C. Schmid, Marianne Schmid Mast and Dario Bombari, "How Mood States Affect Information Processing During Facial Emotion Recognition: An Eye Tracking Study", Department of Work and Organizational Psychology, University of Neuchatel, Switzerland, 2011

[7] Angela Fessl, Ver_onica Rivera-Pelayo, Viktoria Pammer and Simone Braun, "Mood Tracking in Virtual Meetings", FZI Research Center of Information Technologies, Karlsruhe, Germany, 2012.

[8] Dan Liu, Lie Lu and Hong-Jiang Zhang, "Automatic Mood Detection from Acoustic Music Data", Department of Automation Tsinghua University Beijing 100084 China, 2013.

[9] Tsen-Yao Chang, "EMOTIONAL PROBES" AS A USER-CENTRED METHODOLOGY FOR DESIGNING EMOTIONALLY-ENGAGED WEB INTERACTION, Department of creative Design, National Yunlin University of Science \& Technology, Taiwan,2005.

[10] Robert LiKamWa, Yunxin Liu, Nicholas D. Lane and Lin Zhong, "MoodScope: Building a Mood Sensor from Smartphone Usage Patterns", Rice University, Houston, TX Microsoft Research Asia, Beijing, China, 2013.

[11] Bram van de Laar, "Emotion detection in music: A Survey”, b.l.a.vandelaar@student.utwente.nl,2006.

[12] S.P.Khandait, Dr. R.C.Thool, P.D.Khandait, "Automatic Facial Feature Extraction and Expression Recognition based on Neural Network", Deptt of IT, KDKCE, Deptt. of IT, SGGSIET, Deptt. of Etrx, KDKCE, Nagpur, Maharashtra, India, Nanded, Maharashtra, India, Nagpu Maharashtra, India, prapti_khandait@yahoo.co.in.., rcthool@yahoo.com, 2012.

[13] SeungTaek Ryoo, "Emotion Affective Color Transfer", School of Computer Engineering Hanshin Univ. Osan City, South Korea, stryoo@hs.ac.kr,2014.

[14] SeungTaek Ryoo and Jae-Khun Chang, "Emotion Affective Color Transfer Using Feature Based Facial Expression Recognition", School of Computer Engineering Hanshin Univ. Osan City, South Korea, \{stryoo, jchang\}@hs.ac.kr, 2013.

[15] Vinay Bettadapura, "Face Expression Recognition and Analysis: The State of the Art", College of Computing, Georgia Institute of Technology, vinay@gatech.edu, 2012.

\section{Author(s) Profile}

Asma Malik (Born in April 19, 1993) is a student of Fatima Jinnah Women University, department of Software Engineering. She is interested in writing in her field. She had done her internship from PTCL in switching department.

Haleema Inam (Born in July 26, 1996) student of Fatima Jinnah University, department of Software Engineering. She had done her internship from Save the Poor (NGO) in IT department.

Marina Hayat (Born) student of Fatima Jinnah University, department of Software Engineering.

Alia Ashraf Khan (Born) lecturer at Fatima Jinnah University, department of Software Engineering. 